\title{
The Effect of Bloomfield Structuralism Linguistics on English Teaching in Applied Undergraduate Institutions
}

\author{
Wang Yuhong \\ Zhengzhou University of Industrial Technology, School of Foreign Languages, 451151, Henan, China
}

Keywords: Structuralism; Linguistics; Practical application

\begin{abstract}
Bloom-field's structuralist theory of language, just like other theories, is accompanied by profound social background and theoretical background. American anthropologists find Indians indigenous language is dying out, and suffers from no relevant written records, leading to fewer and fewer people to use the Indian language. Meanwhile anthropologists are collecting, compiling and arranging Indian language, and they have developed a set of language programs in practice that can automatically discover and study grammar. Institutions in the preparation of English lesson plans and teachers in the process of practical teaching, cannot be categorized simply by blunt, taking into account the exchange of language characteristics, while taking into account the language structure of the classification of English words and sentences, so that English teaching can be more in line with practical application.
\end{abstract}

\section{Introduction}

Structuralism is one of the relevant research strategies used to analyze language, culture and society in the second half of the twentieth century. Structuralism can be seen as a broad research strategy with different variations. From a broad perspective, structuralism attempts to explore the cultural interrelationships. The relationship between cultural production and recreation is the various practices, phenomena and activities of the ideographs system. Structuralism differences in the object of study, involving food preparation and meal etiquette, religious rituals, games, literary and non-literary texts. In the processing of research to identify the culture of manufacturing and re-manufacturing of the deep structure. There is no clear school of structuralism; different thinking at any time determines the different research strategies, and the development of complex. The French anthropologist Levi-Strauss believes that things can be analyzed according to the structural relations among the components. The universal model in a cultural system, as the product of a constant structure in human thought, determines the mode of development of human society. Structuralism is not simply a philosophical doctrine but a research strategy that is used both by human scientists and by social scientists in their respective fields. The purpose is to hope that the humanities and social sciences can be as precise and scientific as the natural sciences. Structuralism emphasizes the whole, and the whole is logically prioritized. As a complex and unitary entity, the nature of any one component cannot be understood in isolation. Only when placed in a complex and unified network can the two be understood. In any situation, there are no isolated factors, which are determined by other factors in the established factors. Language is a symbolic science. Structuralism opposes the freedom of human choice and decides on research in a variety of structural organizations that focus on human behavior. Saussure, published in 1916, "General Linguistics Course" proposed that as a social product of abstract memory, the language depends on the symbolic system to survive. As a necessary tool for human communication, language naturally arises from a process of natural extinction or unnatural death. Like other theories, the American structuralism language is accompanied by profound social background and theoretical background. American anthropologists find Indians Indigenous language is dying out, suffer from no relevant written records, leading to fewer and fewer people to use Indian language. While anthropologists are collecting, compiling and arranging Indian language, they have developed a set of language programs in practice that can automatically discover and study grammar. College English teaching is very special. How to cultivate students' practical English skills in response to the English test 
grading will also be more and more investigated in college English education.

\section{Take into account the communicative characteristics of language}

Usually, the daily teaching of English, only the first profound understanding of the actual production and application of structuralism, can just right application in English teaching. In the teaching method of listening and speaking, we cannot simply think that the grammar of church students is to understand the meaning of the article. After all, the most basic language is still spoken. Teachers should discuss and communicate with students while stimulating students' interest in learning, and strengthen the communication of spoken language when they understand how to learn how to communicate. Listening, speaking, reading, writing and translating are the five basic skills of English learning. In traditional teaching strategies, the students' ability to read and write is too high for students to ignore the original intention of language production while ignoring the ability of listening and speaking. Under the current education system, paying attention to the liquidity of language is the foundation of respecting the original intention of language formation. Only by focusing on language features can we improve the practical ability of language use. Grammar research should be based on the form of language, cannot be disturbed, in terms of type classification, simple morphemes, words, phrases, sentences collectively referred to the grammatical form (4). In traditional teaching, the grammar education in large schools is specified in the same way, but all types cannot be regulated according to them. Therefore, schools in the preparation of English lesson plans and teachers in the process of practical teaching cannot be categorized simply categorized blunt, taking into account the exchange of language features.

\section{The formation of language features}

The science of linguistic categories cannot be defined in philosophical terms, except that linguistic categories can be considered consistent with actual categories. In English, the singular and plural differences between nouns, the singular dominant word can only be connected with the singular fixed verb, while the plural dominant linguistic word can only be connected with complex fixed verbs to modify the pronoun different. In the actual teaching of English, we should pay close attention to these types of thin classification, so that English teaching rules to follow. Language can cover the layers of lines, discourse cannot instantly observed the composition of the word structure to observe at the same time, to comply with the principle of direct composition (5). In college English teaching practice, how to remember words efficiently has always been a source of distress for many students. If students are guided in their understanding of language, they can cover the layers in a linear manner, which is of great help to the memory of words. The study of grammar in linguistics has proposed many laws of innovation, contrast and segmentation. When verbal form appears as a larger form, the recognition of morpheme is in an internal position, and if the morpheme is not in an internal position, the recognition of the morpheme is in an absolute position. In the practice of high school English education, we should examine the independent language form of each sentence and can not include any grammatical structure into any larger language form. In recognition of this, the reason for the dislocation of the sentence will be greatly improved. Bragg phoneme school, also known in structuralism as "structural function" and "functional school", mainly in the study of phonetics. The internal components of language determine the internal functions of the language and constitute a complete model and system in the process of comparison of each component. If we analyze the language formally and physically, the language will form a rigorous theoretical system of linguistics. The structural language school in the United States places more emphasis on the formal description of language materials and language structures. Structural linguistic spoken language, focusing on the specific application of the recording language, in the popularization and application of English as a popular language in the world today, the oral English does not intend to conform to the law of the times. In English practice, in addition to training students in problem-solving skills, but also pay attention to students' oral English training, so that students obtain practical English skills. 


\section{Analysis of college students listening teaching}

Language as a process of information processing, in listening teaching, to improve the efficiency of students' listening comprehension, it is necessary to classify and conclude the homonyms and synonyms related to the resolving power so as to achieve the purpose of classification of morphemes. English listening as a process of receiving information, improve listening and speaking ability, in addition to achievement, but also the actual communicative competence. The teacher's responsibility is to explanatory improve the quality of teaching so as to truly help students improve their English listening comprehension, so as to increase the effectiveness of classroom teaching and improve the teaching effect. The vast majority of students will study the purpose of college English in the non-practical application of the English test grading. English as a common language, given to the audience, the ultimate goal is still to exchange use. The structuralist approach to language research in the United States can cite students' distracting attention to solving problems, gradually dispersing them into listening and speaking, grammar learning and vocabulary memory, thereby strengthening their own practical ability in English. Characteristics of Listening Self-efficacy Scale of Non-English Majors, The scale has the characteristics of high reliability, easy operation and strong pertinence. The statistical analysis results of quantitative data show that the self-efficacy scales of non-English majors that we have developed have good reliability and validity and can better detect the self-efficacy of non-English majors in English listening comprehension. Topic Description is simple and straightforward. Usually students complete the scale only fifteen minutes or so, will not cause the students tired and disgusted. In addition, the questionnaire filled the gap of self-efficacy scales in the lack of specific subjects and specific skills of the professional scale, and the establishment of scales limited to non-English majors in English listening self-efficacy Sensory amount. (B) the relationship between listening self-efficacy and English achievement The correlation between listening self-efficacy and their four grades of English scores, the correlation coefficient of 0.431 , a moderate correlation. This also confirms the conclusions of other researchers: high achievement level students tend to be more self-efficacy than low grade students. Bandeaux.'s research shows that the formation of self-efficacy is closely related to past successes and failures, while those with high English proficiency tend to gain more successful experience. As a result, they tend to show more confidence and self-efficacy in facing the same tasks. Therefore, in the usual college English listening teaching, how to guide students to enhance their sense of self-efficacy, yet to be front-line teachers and researchers continue to study.

\section{Conclusion}

In the process of compiling the English teaching plan and practice teaching in English, teachers cannot be categorized simply into hardcore classification, taking into account the communicative characteristics of language, classifying English words and sentences while taking into account the language structure, and enabling English teaching More in line with the practical application, improve college students' English level.

\section{References}

[1] Chen Xi-amen. "An Analysis of the Enlightenment of American Structuralism Linguistics on English Audio-visual Teaching" [J]. Science \& Technology Perspective, 2011, (01)

[2] WANG Yuan-lane. "A Brief Introduction to Structuralism Linguistics for Foreign Language Teaching Enlightenment" [G] Ginsu Science and Technology, 2010, (04)

[3] LIANG Rue. "American Structuralism Linguistics and Foreign Language Teaching" [J]. Science and Technology Information, 2007, (26)

[4] Lino Inhuman. Psychological factors - English learning cannot be ignored factor [K] mad English Teachers' Edition, 2006 (10).

[5] Wu Inhuman \& Bhang Jun. Theoretical basis of teacher professional competence test education (General Version) [M]. Beijing: Capital Normal University Press, 2009: 181.

[6] Thang Congeal. Cultural Linguistics [M]. Shanghai: Xi'an University Press, 2009: 7. 